\title{
HUBUNGAN ANTARA PENGUASAAN POSSESSIVPRONOMEN DENGAN KETERAMPILAN MENULIS KALIMAT SEDERHANA BAHASA JERMAN
}

\author{
Nini Kasvia Haris ${ }^{1}$, Misnah Mannahali², dan Muhammad Anwar ${ }^{3}$ \\ Konsulat Jenderal Republik Federal Jerman, Makassar ${ }^{1}$ \\ Fakultas Bahasa dan Sastra, Universitas Negeri Makassar ${ }^{2,3}$ \\ Email: ninikasviajaya@gmail.com ${ }^{1}$
}

\begin{abstract}
ABSTRAK
Penelitian ini bertujuan untuk mengetahui hubungan antara penguasaan Possessivpronomen dengan keterampilan menulis kalimat sederhana bahasa Jerman siswa kelas XI SMA Negeri 11 Makassar. Pengumpulan data pada penelitian ini dilakukan dengan tes tertulis. Data dianalisis dengan korelasi Product Moment. Populasi penelitian ini adalah seluruh siswa kelas XI IPA, dengan jumlah 252 siswa. Sampel penelitian ini adalah 30 siswa kelas XI IPA 1 yang dipilih melalui teknik Purposive Sampling. Hasil analisis data melalui korelasi Product Moment, diperoleh nilai $\mathrm{r}_{\mathrm{h}}=(0,632)>\mathrm{r}_{\mathrm{t}}=(0,361)$, hasil penelitian menunjukkan bahwa ada hubungan positif yang signifikan antara penguasaan Possessivpronomen dengan keterampilan menulis kalimat sederhana bahasa Jerman siswa kelas XI SMA Negeri 11 Makassar $(r=0,632)$.
\end{abstract}

Kata Kunci: Possessivpronomen, Keterampilan Menulis, Bahasa Jerman.

\begin{abstract}
This study aims to determine the relationship between Possessivpronomen mastery with the ability to write simple sentences for class XI students of SMA Negeri 11 Makassar. Data collection in this study was carried out with a written test. Data is analyzed by revealing product moment. The population of this study were all students of class XI IPA, with a total of 252 students. The sample of this study was 30 students of class XI Science 1 who were selected through purposive sampling technique. The results of the analysis through instant Product Moment, obtained the value of $\mathrm{rh}=(0.632)>\mathrm{rt}=(0.361)$, the results showed that there was a significant positive relationship between Possessivpronomen mastery with the ability to write simple student sentences $(r=0.632)$.
\end{abstract}

Keywords: Possessivpronomen, Writing Skill, German Language.

\section{PENDAHULUAN}

Bahasa adalah suatu alat yang digunakan untuk berkomunikasi, berinteraksi, baik bahasa lisan maupun tulisan (Handayani, 2013; Yusri, 2015,2016). Dengan bahasa, manusia dapat menyampaikan pikiran, gagasan, konsep atau perasaan. Berkomunikasi dengan baik harus menggunakan bahasa yang baik pula. Menguasai bahasa asing merupakan salah satu cara mengembangkan mutu pendidikan di Indonesia terutama dalam mendapatkan pekerjaan untuk menunjang kehidupan. Mendapatkan pekerjaan tidak hanya bermodalkan pendidikan tinggi, namun harus dibekali dengan penguasaan bahasa asing. 
Bahasa asing sangat diperlukan di era globalisasi. Kegunaan bahasa asing yang utama sebagai media komunikasi antarnegara.

Bahasa asing yang dijadikan sebagai bahasa internasional yaitu bahasa Inggris. Bukan hanya bahasa Inggris yang harus dikuasai untuk berkomunikasi di dunia internasional tetapi juga bahasa Asing yang lain, misalnya bahasa Mandarin, bahasa Arab, dan bahasa Jerman.

Pelajaran bahasa Jerman di Indonesia telah diajarkan di tingkat Sekolah Menengah Atas (SMA), Sekolah Menengah Kejuruan (SMK), dan Madrasah Aliyah (MA). Salah satu sekolah yang mengajarkan bahasa Jerman ialah SMA Negeri 11 Makassar. Pengajaran bahasa Jerman tidak lepas dari empat aspek yang ada di dalam bahasa tersebut. Dalam Kurikulum Tingkat Satuan Pendidikan (KTSP), pelaksanaan pembelajaran bahasa Jerman di SMA terdiri dari empat aspek yang dipelajari yaitu: kemampuan menyimak (Hörverstehen), keterampilan menulis (Schreibfertigkeit), keterampilan berbicara (Sprechfertigkeit), dan kemampuan membaca (Leseverstehen). Keempat aspek ini saling menunjang satu sama lain dan tidak dapat dipisahkan dalam proses pembelajaran.

Kemampuan menyimak dan kemampuan membaca merupakan kemampuan berbahasa yang bersifat reseptif, sedangkan keterampilan berbicara dan keterampilan menulis merupakan keterampilan berbahasa yang bersifat produktif. Untuk menguasai keempat aspek berbahasa tersebut dituntut adanya penguasaan gramatik dan penguasaan kosakata yang baik. Tanpa penguasaan gramatik dan kosakata seseorang tidak akan mampu mengungkapkan pikiran, pendapat, serta perasaan baik secara lisan maupun tulisan. Semakin baik penguasaan gramatik dan kosakata seseorang, semakin jelas pula bahwa orang tersebut terampil dalam berbahasa. Oleh karena itu, aspek kebahasaan seperti gramatik dan kosakata sangat dibutuhkan dalam pembelajaran bahasa Jerman.

Berdasarkan penjelasan tersebut dapat disimpulkan bahwa tujuan yang harus dicapai dalam pembelajaran bahasa Jerman adalah siswa dapat mengembangkan keempat aspek keterampilan berbahasa yang diajarkan. Grammatik dan kosakata merupakan faktor pendukung dalam pencapaian keempat aspek tersebut. Dari empat aspek berbahasa tersebut, keterampilan menulis merupakan keterampilan yang sulit untuk dikuasai siswa. Banyak faktor yang menjadi penghambat dalam keterampilan menulis antara lain penguasaan gramatik dan kosakata yang kurang memadai.

Keberhasilan pembelajaran menulis tidak dapat dicapai secara instan, dengan kata lain membutuhkan waktu yang lama. Dalam hal ini peran guru sangat penting untuk siswa, siswa harus banyak berlatih menulis bahasa Jerman baik di kelas maupun di luar kelas. Peran guru sangat besar untuk mengembangkan kemampuan siswa dalam menulis (Qalbi et all, 2017; Mantasiah et all, 2017). Guru dituntut menggunakan metode, pendekatan, atau teknik yang tepat dalam menerapkan materi menggunakan media yang tepat agar siswa lebih terampil pada pembelajaran. Beberapa penelitian sebelumnya telah menujukkan bahwa kemampuan guru dalam mengembangkan model ataupun media pembelajaran dapat memengaruhi hasil belajar siswa (Quddus et all, 2017; Mantasiah et all, 2018; Tenri et all, 2017; Romadloni et all, 2017). 
Pelajaran bahasa Jerman mempunyai banyak aturan, salah satunya ialah penggunaan kepunyaan atau kepemilikan (Possessivpronomen) yang biasa digunakan dalam pembentukan kalimat sederhana. Setiap kata benda dalam bahasa Jerman memiliki 'artikel' yang harus dikuasai oleh siswa. Penguasaan artikel sangat berpengaruh pada penggunaan Possessivpronomen. Kemampuan siswa menguasai Possessivpronomen berpotensi menjadi penyebab kurang mampunya siswa dalam memahami penggunaan Possessivpronomen bahasa Jerman.

Berdasarkan pengamatan penulis saat melakukan Praktik Pengalaman Lapangan II pada tanggal 24 September hingga 02 November 2015, keterampilan menulis siswa masih belum memenuhi kriteria penulisan bahasa Jerman. Hasil pengamatan tersebut menunjukkan bahwa siswa masih mengalami kesulitan dalam menulis atau membuat kalimat sederhana dalam bahasa Jerman. Salah satu kesulitan siswa dalam menuangkan ide berupa kalimat bahasa Jerman yaitu kurangnya penguasaan Possessivpronomen. Hal ini menjadi penghambat siswa dalam menyusun kata menjadi kalimat yang benar sesuai struktur kalimat bahasa Jerman. Materi bahasa Jerman yang diberikan oleh guru sudah sesuai dengan standar kompetensi dan kompetensi dasar berdasarkan kurikulum. Peran guru dalam pembelajaran bahasa Jerman dapat dikatakan baik.

Selain itu, keterbatasan alokasi waktu yang dimiliki guru untuk mengajarkan bahasa Jerman juga menjadi faktor penghambat, sehingga guru belum dapat menyampaikan materi menulis secara keseluruhan. Akibatnya kesempatan siswa untuk berlatih menulis kurang dan guru juga jarang memberikan contoh membuat kalimat bahasa Jerman. Pernyataan di atas didukung oleh penelitian sebelumnya, yang dikemukakan oleh Rahman (2015) bahwa keterampilan menulis yang berhubungan dengan penguasaan gramatik siswa termasuk dalam kategori cukup dengan nilai rata-rata 23,8 atau dengan presentase $72,39 \%$. Penelitian lain dari Sudiana (2008) mengenai Possessivpronomen menyimpulkan bahwa kemampuan siswa dalam penggunaan deklinasi Possessivpronomen termasuk dalam kategori tidak cukup dengan presentase 44,32\%. Sedangkan dalam penelitian Mulyati (2008) menjelaskan bahwa ada pengaruh yang signifikan antara penguasaan gramatik terhadap keterampilan menulis bahasa Jerman ( $\left.t_{\text {hitung }}=8,152>t_{\text {tabel }}=1,978\right) \quad$ dengan nilai sumbangan efektif sebesar 19,54\%. Berdasarkan uraian di atas, maka penulis ingin mengetahui apakah ada hubungan antara penguasaan Possessivpronomen dan keterampilan siswa dalam menulis kalimat sederhana bahasa Jerman.

\section{METODE PENELITIAN}

$\begin{array}{ccr}\text { Penelitian } & \text { ini menggunakan dua } \\ \text { variabel } & \text { yaitu } & \text { penguasaan }\end{array}$
Possessivpronomen bahasa Jerman siswa kelas XI IPA sebagai variabel bebas (X) dan keterampilan menulis kalimat sederhana bahasa Jerman siswa kelas XI IPA sebagai variabel terikat (Y). Penelitian ini merupakan penelitian deskriptif korelasi yang bertujuan untuk mengetahui hubungan antara variabel (Jufri, 2017; Jufri 2017). Variabel dalam hal ini adalah penguasaan Possessivpronomen bahasa Jerman dengan keterampilan menulis kalimat sederhana bahasa Jerman siswa kelas XI SMA Negeri 11 Makassar.

Penguasaan possessivpronemen dalam bahasa Jerman yang dimaksud dalam penelitian ini adalah kemampuan siswa dalam 
menggunakan possessivpronomen dalam bentuk Nominativ dan Akkusativ sesuai dengan artikel kata benda. Keterampilan menulis yang dimaksud dalam penelitian ini adalah keterampilan siswa dalam menulis kalimat sederhana dengan menggunakan Possessivpronomen yang terdiri dari subjek, predikat dan objek berdasarkan tema yang diberikan "die Familie"

Populasi dalam penelitian ini adalah seluruh siswa kelas XI IPA SMA Negeri 11 Makassar yang terdiri atas tujuh kelas dengan jumlah keseluruhan siswa kelas XI IPA dengan jumlah 252 orang. Penulis menggunakan teknik purposive sampling. Kelas yang dijadikan sasaran penelitian yaitu kelas XI IPA 1 SMA Negeri 11 Makassar. Dengan pertimbangan, penulis memilih kelas ini sebagai sasaran penelitian karena kelas ini masih kurang dalam penguasaan Possessivpronomen dan menulis kalimat sederhana.

Untuk memeroleh data dalam penelitian ini digunakan dua jenis tes yaitu tes penguasaan Possessivpronomen bahasa Jerman dan tes keterampilan menulis kalimat sederhana bahasa Jerman. Tes penguasaan Possessivpronomen ini terdiri atas soal bentuk tes isian yang terdiri dari 25 butir soal. Setiap butir soal isian diberi bobot 1. Jika siswa menjawab soal dengan benar mendapatkan 1 skor, jika salah tidak mendapat skor atau 0 . Jadi skor maksimal dari tes penguasaan Possesivpronomen ini adalah 25. Sedangkan tes keterampilan menulis kalimat sederhana terdiri atas 10 soal. Dalam 1 soal terdiri dari 3 pertanyaan, setiap pertanyaan diberi skor maksimal 3. Jadi, dalam satu nomor skor maksimalnya adalah 9. Jika siswa menulis kalimat dengan struktur, kosakata dan penulisan dengan benar maka diberikan 3 skor, jika siswa menulis kalimat dengan struktur, kosakata, dan penulisan kurang tepat maka diberikan 2 skor, jika siswa menulis kalimat salah atau tidak sesuai maka diberikan 1 skor, dan jika siswa tidak menulis kalimat sama sekali maka tidak diberikan skor sama sekali. Jadi skor maksimal keseluruhan tes keterampilan menulis kalimat sederhana ini adalah 90. Penilaian ini dikembangkan oleh Djiwandono (1996).

Data penilaian ini diolah dengan menggunakan teknik analisis korelasi Product Moment untuk mengetahui hubungan signifikan antara penguasaan Possesivpronomen bahasa Jerman dan keterampilan menulis kalimat sederhana bahasa Jerman siswa kelas XI SMAN 11 Makassar. Setelah diperoleh nilai r, maka hasil perhitungan dikonsultasikan dengan nilai $\mathrm{r}$ Product Moment ( $\mathrm{r}_{\text {tabel }}$ ) pada taraf signifikan 0,05 . Jika nilai $r$ yang diperoleh sama atau lebih besar dari nilai $r$ tabel $\left(r_{h}>r_{t}\right)$ maka hipotesis penelitian $\left(\mathrm{H}_{1}\right)$ diterima. Sebaliknya, jika jumlah nilai r yang diperoleh ( $r_{\text {hitung }}$ ) lebih kecil dari nilai $r$ tabel $\left(r_{h}<r_{t}\right)$ maka hipotesis penelitian ditolak.

\section{HASIL DAN PEMBAHASAN}

\section{Hasil Analisis Data Tes Penguasaan Possessivpronomen}

Bagian ini menjelaskan hasil analisis data tentang nilai yang diperoleh siswa dalam penguasaan Possessivpronomen bahasa Jerman. Berdasarkan data penelitian yang telah diolah untuk variabel penguasaan Possessivpronomen, skor terendah yang dicapai siswa adalah 6 dan skor tertinggi yang dicapai siswa adalah 20 . Berikut distrubusi frekuensi variabel penguasaan Possessivpronomen bahasa Jerman dapat dilihat pada tabel: 
Tabel 1.

Distribusi Frekuensi Nilai Tes Penguasaan Possessivpronomen Bahasa Jerman

\begin{tabular}{cccc}
\hline Kelas Interval & Interval Skor & Frekuensi & Presentase (\%) \\
\hline 1. & $6-8$ & 3 & 10 \\
2. & $9-11$ & 4 & 13,3 \\
3. & $12-14$ & 5 & 16,6 \\
4. & $15-17$ & 12 & 40 \\
5. & $18-20$ & 6 & 20 \\
6. & 21 ke atas & 0 & 0 \\
& Jumlah & 30 & 100 \\
\hline
\end{tabular}

Tabel di atas menunjukkan bahwa dari 30 siswa yang menjadi sempel terdapat 3 siswa (10\%) yang berada pada interval 68,4 siswa $(13,3 \%)$ berada pada interval 911,5 siswa $(16,6 \%)$ berada pada interval 12-14, 12 siswa (40\%) berada pada interval $15-17,6$ siswa $(20 \%)$ berada pada interval 18-20, sedangkan tidak ada siswa yang berada pada kelas interval 21 keatas. Data tersebut menyatakan bahwa dari 30 siswa diperoleh kelas interval yang memiliki frekuensi tertinggi berada pada interval 1517 dengan frekuensi siswa 12 siswa (40\%).

\section{Hasil Analisis Data Tes Keterampilan Menulis Kalimat Sederhana}

Bagian ini menyajikan hasil analisis data tentang nilai yang diperoleh siswa dalam tes keterampilan menulis kalimat sederhana bahasa Jerman. Berdasarkan data penelitian yang telah diolah, diperoleh skor terendah yang dicapai siswa adalah 50 dan skor tertinggi yang dicapai siswa adalah 81 . Berikut distribusi frekuensi variabel keterampilan menulis bahasa Jerman dapat dilihat pada tabel:

Tabel 2.

Distribusi Frekuensi Nilai Tes Keterampilan Menulis Bahasa Jerman Siswa

\begin{tabular}{|c|c|c|c|}
\hline Kelas Interval & Interval Skor & Frekuensi & Presentase $(\%)$ \\
\hline 1 & $50-55$ & 4 & 13,33 \\
\hline 2. & $56-61$ & 1 & 3,33 \\
\hline 3. & $62-67$ & 2 & 6,66 \\
\hline 4. & $68-73$ & 14 & 46,66 \\
\hline 5. & $74-79$ & 7 & 23,33 \\
\hline 6. & 80 ke atas & 2 & 6,66 \\
\hline \multicolumn{2}{|c|}{ Jumlah } & 30 & 100 \\
\hline
\end{tabular}

Tabel di atas menunjukkan bahwa dari 30 siswa yang menjadi sempel diperoleh 4 siswa $(13,33 \%)$ berada pada interval 50-55, 1 siswa $(3,33 \%)$ berada pada interval 56-61, 2 siswa $(6,66 \%)$ berada pada interval 62-67, 14 siswa $(46,66 \%)$ berada pada interval $63-73,7$ siswa $(23,33 \%)$ berada pada interval 74-79), 2 siswa $(6,66 \%)$ berada pada interval 80 ke atas. 
Data tersebut menyatakan bahwa dari 30 siswa diperoleh kelas interval yang memiliki frekuensi tertinggi berada pada interval 68-73 dengan frekuensi siswa 14 siswa (46,66\%).

\section{Hasil Analisis Korelasi Product Moment}

Berdasarkan hasil analisis Korelasi Product Moment diperoleh koefisien korelasi yaitu 0,632. Selanjutnya untuk mengetahui bahwa koefisien korelasi sebesar 0,632 merupakan koefisien yanhg bermakna atau signifikan dan hasil analisis data tersebut dapat digunakan sebagai dasar generalisasi atau kesimpulan terhadap populasinya, maka nilai koefisien korelasi hitung ( $r$ hitung disingkat $r_{h}$ ) sebesar 0,632 dibandingkan dengan koefisien korelasi tabel ( $\mathrm{r}$ tabel singkat $r_{t}$ ) sebesar 0,361 yang terdapat dalam tabel nilai $r$ Product Moment. Dengan ketentuan apabila $\mathrm{r}$ hitung $>\mathrm{r}$ tabel maka korelasinya signifikan dan apabila $r$ hitung $\leq \mathrm{r}$ tabel berarti korelasinya tidak signifikan.

Cara menentukan $\mathrm{r}$ hitung adalah dengan melihat angka sebelah kiri tabel yang menunjukan jumlah sampel $(\mathrm{N})$ yang diteliti. Dalam penelitian ini jumlah sampel yang digunakan $\mathrm{N}=30$. Kemudian melihat angka yang merupakan koefisien korelasi pada taraf signifikan 0,05. Pada taraf signifikansi 0,05 menunjukkan koefisien korelasi sebesar 0,361 (lihat lampiran 6 halaman 58). Berdasarkan koefisien-koefisien korelasi yang diperoleh, dapat ditulis: $\left(r_{\mathrm{h}}=0,632>\mathrm{r}_{t}=0,361\right)$. Hal ini dapat diartikan bahwa $r$ hitung sebesar 0,632 lebih besar dari $r$ tabel pada taraf signifikansi 0,05 yaitu 0,361 . Dengan demikian diinterprestasikan bahwa ada hubungan yang signifikan antara penguasaan Possessivpronoemen (X) dengan keterampilan menulis kalimat sederhana bahasa Jerman (Y).

\section{Pengujian Hipotesis}

Sebagaiamana yang telah dikemukakan sebelumnya, bahwa hipotesis dalam penelitian ini adalah terdapat hubungan positif yang signifikan antara penguasaan Possessivpronomen dengan keterampilan menulis kalimat sederhana bahasa Jerman. Untuk menguji hipotesis ini digunakan rumus korelasi Product Moment. Pada bab terdahulu telah dikemukakan tentang ketentuan dalam pengujian hipotesis, yaitu jika nilai $r_{\text {hitung }}$ yang diperoleh sama atau lebih besar dari nilai $r_{\text {tabel }}$ $\left(r_{h}>r_{t}\right)$ maka hipotesis penelitian $\left(H_{1}\right)$ diterima. Sebaliknya, jika nilai $r$ yang diperolah ( $r$ hitung) lebih kecil dari nilai $r$ dalam tabel $\left(r_{h}<r_{t}\right)$ maka hipotesis penelitian $\left(\mathrm{H}_{1}\right)$ ditolak. Berdasarkan hasil analisis dapat disimpulkan bahwa $\mathrm{H}_{0}$ yang menyatakan tidak ada hubungan antara penguasaan gramatik dengan keterampilan menulis kalimat sederhana bahasa Jerman ditolak. Sebaliknya $\mathrm{H}_{1}$ yang menyatakan bahwa ada hubungan positif yang signifikan antara penguasaan Possessivpronomen dengan keterampilan menulis kalimat sederhana bahasa Jerman dinyatakan diterima.

Berdasarkan hasil analisis data yang diolah menggunakan rumus korelasi Product Moment, diperoleh nilai $\mathrm{r}$ hitung $\left(\mathrm{r}_{\mathrm{h}}\right)$ adalah 0,632. Untuk mengetahui apakah $r_{\text {hitung }}$ signifikan atau tidak atas dasar signifikan 0,05, maka $\mathrm{r}_{\mathrm{h}}$ dikonsultasikan dengan tabel $\mathrm{r}$ Product Moment. Dari tabel tersebut diketahui bahwa dengan jumlah subjek $(\mathrm{N})=30$, maka: nilai $r_{\text {tabel }}$ pada taraf signifikan $0,05=0,361$. Dengan demikian nilai $r_{\text {hitung }}$ yang diperoleh lebih besar dari $r_{\text {tabel }}$ yaitu $(0,632>0,361)$ pada taraf signifikansi 0,05. Dengan demikian hipotesis penelitian $\left(\mathrm{H}_{1}\right)$ yang mengatakan bahwa: Ada hubungan positif yang signifikan antara penguasaan Possessipronomen dengan keterampilan menulis karlimat sederhana bahasa Jerman siswa diterima. Untuk 
mengetahui penafsiran kekuatan koefisien korelasi tersebut, nilai $r$ hitung yang diperoleh melalui teknik analisis data product moment yakni 0,632 dikorelasikan pada tabel interpretasi $\mathrm{r}$, sehingga diperoleh kesimpulan bahwa kekuatan hubungan kedua variabel tersebut tergolong dalam kategori kuat.

Data hasil penelitian tes penguasaan Possessivpronomen terdiri atas tes melengkapi kalimat dengan Possessivpronomen, skor maksimal soal ini adalah 25. Dari hasil penelitian skor tertinggi yang didapatkan oleh siswa yaitu 20, sedangkan skor terendah yang didapatkan oleh siswa yaitu 6. Siswa yang mendapat nilai tertinggi terdapat pada nomor urut 20 dan siswa yang mendapat nilai terendah terdapat pada nomor urut 24 (lihat lampiran 2 halaman 54). Berdasarkan hasil analisis data dapat diketahui bahwa skor rata-rata yang diperoleh siswa pada tes penguasaan Possessivpronomen 14,3 (57,2\%).

Penilaian tes keterampilan menulis kalimat sederhana terdiri dari empat penilaian. Fokus penilaian adalah struktur, kosakata dan penulisan. Skor maksimal pada tes keterampilan menulis kalimat sederhana ini adalah 90. Skor tertinggi yang didapatkan oleh siswa yaitu 85 , sedangkan skor terendah yang didapatkan oleh siswa yaitu 50. Siswa yang mendapat nilai tertinggi terdapat pada nomor urut 12 dan siswa yang mendapat nilai terendah terdapat pada nomor urut 25. Berdasarkan hasil analisis data dapat diketahui bahwa skor rata-rata yang diperoleh siswa pada tes keterampilan menulis kalimat sederhana 69,4 (77,11\%).

Hasil penelitian ini menunjukkan adanya hubungan yang signifikan antara penguasaan Possessivpronomen dengan keterampilan menulis kalimat sederhana. Terbukti pada hasil tes penguasaan
Possessivpronomen dan tes keterampilan menulis kalimat sederhana, ada beberapa siswa yang mendapatkan nilai seimbang antara penguasaan Possessivpronomen dan keterampilan menulis kalimat sederhana siswa, yaitu siswa nomor urut 12, 15, dan 29. Siswa nomor urut 12 mendapatkan skor 19 pada tes penguasaan Possessivpronomen dan mendapatkan skor 81 pada tes keterampilan menulis kalimat sederhana, siswa nomor urut 15 mendapatkan skor 20 pada tes penguasaan Possessivpronomen dan mendapatkan skor 80 pada tes keterampilan menulis kalimat sederhana, dan siswa nomor urut 29 mendapatkan skor 20 pada tes penguasaan Possessivpronomen dan mendapatkan skor 77 pada tes keterampilan menulis kalimat sederhana. Skor yang diperoleh siswa pada penguasaan Possessivpronomen dan keterampilan menulis kalimat sederhana kemudian dianalisis dengan menggunakan teknik korelasi Product Moment, dari hasil perhitungan diperoleh hasil bahwa $r_{\text {hitung }}$ lebih besar dari pada $r_{\text {tabel }}\left(r_{h}>r_{t}\right)$ yaitu 0,632 >0,361. Dengan demikian dapat disimpulkan bahwa terdapat korelasi yang signifikan antara penguasaan Possessivpronomen dengan keterampilan menulis kalimat sederhana bahasa Jerman.

Penguasaan Possessivpronomen merupakan salah satu faktor yang penting dalam keterampilan menulis, termasuk keterampilan menulis kalimat sederhana. Dalam proses penyusunan kata menjadi kalimat dalam bahasa Jerman memerlukan penguasaan possessivpronomen sebagai kelengkapan struktur kalimat. Oleh sebab itu, siswa dituntut untuk menguasai possessivpronomen agar dapat menciptakan tulisan yang berkualitas. Siswa yang penguasaan possessivpronomennya rendah mengakibatkan penulisannya menjadi lambat, 
karena mereka bingung memulai menulis dan juga bingung possessivpronomen yang seperti apa yang tepat digunakan. Jadi dapat dikatakan bahwa siswa yang penguasaan possessivpronomennya rendah lebih membutuhkan waktu lama dalam menulis kalimat yang telah dikonsepkan, sebaliknya penguasaan possessivpronomennya baik, lebih cepat dan tepat dalam menulis kalimat. Menulis bahasa Jerman juga tidak harus dalam ruang kelas saja saat guru memberi tugas tetapi menulis juga harus dilakukan di luar kelas agar lebih terlatih dan lebih memiliki wawasan yang luas tentang bahasa Jerman.

Berdasarkan beberapa penjelasan di atas dapat disimpulkan bahwa salah satu faktor yang mempengaruhi keterampilan menulis kalimat sederhana bahasa Jerman bukan hanya penguasaan possessivpronomen saja. Namun terdapat beberapa faktor lain yang berkonrtibusi, seperti penguasaan kosakata, penguasaan artikel yang menjadi dasar pembentukan possessivpronomen, penempatan kata kerja dan menulis juga membutuhkan latihan-latihan. Dengan demikian dapat disimpulkan bahwa hasil penelitian ini menunjukkan ada hubungan yang signifikan antara penguasaan possessivpronomen dengan keterampilan menulis kalimat sederhana bahasa Jerman temuan ini sejalan dengan teori-teori yang dikemukanan sebelumnya pada bab II.

\section{KESIMPULAN}

Berdasarkan analisis data yang telah dipaparkan sebelumnya, dapat ditarik kesimpulan sebagai berikut:

1. Skor rata-rata yang diperoleh siswa pada tes penguasaan possessivpronomen adalah 14,3 atau $(57,2 \%)$.
2. Skor rata-rata yang diperoleh siswa pada tes keterampilan menulis karangan sederhana adalah 69,4 atau $(77,11 \%)$.

3. Terdapat hubungan antara penguasaan Possessivpronomen dengan keterampilan menulis kalimat sederhana bahasa Jerman. Hubungan ini ditunjukkan dengan koefisien korelasi sebesar 0,632 yang termasuk pada kategori kuat.

\section{DAFTAR PUSTAKA}

Arikunto, Suharsimi. (2006). Prosuder Penelitian Suatu Pendekatan Praktik. Jakarta: PT Nireka Cipta

Bensch, Norbert. (2011). GrundstufenGrammatik. Hueber: München.

Chaer, Abdul. (2008). Morfologi Bahasa Indonsia (Pendekatan Proses). Jakarta: Rinka Cipta

Djiwandono, M. Soernardi. (1996). Tes Bahasa Dalam Pengajaran. Bandung: ITB Bandung

Drodowski, G. (2003). DUDEN Duetsches Universalwörterbuch. Mannheim: Bibliographisches Institut \& F.A Bruckhaus AG.

Engel, Ulrich. (1992). Deutsche Grammatik. Julius Groos: Heidelberg

Funk, dkk. (2014). Studio A- Deutsch als Fremdsprache Kurs- und Übungsbuch. Jakarta: Ikrar Mandiriabadi

Handayani, Y. (2013). Representasi Tindak Tutur Calon Gubernur Sulawesi Selatan: Analisis Wacana Kesopanan Berbahasa. HubsAsia, 9(2).

Haryadi, Moh. (2009). Statistik Pendidikan. Banyuwangi: Prestasi Pustakaraya.

Helbig dan Buscha. (2001). Deutsche Grammatik. Berlin: Langenscheidt 
JUFRI, J. (2007). Metode Penelitian Bahasa, Sastra dan Budaya.

Jufri, J. (2007). Metode Penelitian Bahasa. Sastra dan Budaya.

JUFRI, J. (2017). Strategi Pembelajaran Bahasa.

Kasim. (2013). Deutsch ist einfach für SMA Klasse XI. Solo: PT. Tiga Serangkai Pusataka Mandiri

Kusumaningsih, Dewi dkk. (2013). Terampil Berbahasa Indonesia. Yogyakarta: C.V. Andi Offset.

Mantasiah, R. (2018, June). Pay It Forward Model in Foreign Language Learning to Increase Student's Self Efficacy and Academic Motivation. In Journal of Physics: Conference Series (Vol. 1028, No. 1, p. 012178). IOP Publishing.

Mantasiah, R., Juffri, J., \& Yusri, Y. (2017). Keefektifan Model Pembelajaran Jaring Laba-Laba (Webbed) dalam Keterampilan Menulis Karangan Sederhana Bahasa Jerman. Indonesian Journal of Educational Studies, 20(2).

Müller, Wolfgang. (2003). Das Bedeutengswörterbuch

Bibliographischs Institut Mannheim: Dudenverlag

Mulyati, Sri. (2011). Pengaruh Penguasaan Kosakata, Penguasaan Gramatik, Terhadap Keterampilan Menulis Bahasa Jerman Peserta Didik Kelas XI SMA Negeri 1 Imogiri Bantul. (Jurnal). Yogyakarta: Jurusan Pendidikan Bahasa Jerman UNY

Nurgiyantoro, Burhan. (2001). Penilaiaan dalam Pengajaran Bahasa dan Sastra. Yogyakarta: BPFE.
Pringgawidagda, Suwarna. (2002). Strategi Penguasaan Bahasa. Bandung: Adicitra

Putrsyasa, Ida Bagus. (2008). Analisis Kalimat. Jakarta: Erlangga

Qalbi, U. N., Mantasiah, R., Jufri, J., \& Yusri, Y. (2017). Efektivitas Model Pembelajaran Kooperatif Tipe Teams Games Tournaments dalam Keterampilan Menulis Bahasa Jerman Siswa Kelas XII IPA SMA Negeri 1 Bontonompo Kabupaten Gowa. Indonesian Journal of Educational Studies, 20(1).

Qudus, M., \& Yusri, Y. (2017). Keefektifan Penggunaan Metode Audio Lingual dalam Pembelajaran Kemampuan Menyimak Bahasa Jerman. Indonesian Journal of Educational Studies, 20(2).

Rahman, Niaryanti. (2015). Hubungan Antara Penguasaan Gramatik Dengan Keterampilan Menulis Karangan Sederhana Bahasa Jerman Siswa Kelas Xi Sma Negeri 2 rantepao Kabupaten Toraja Utara. (Skripsi). Makassar: Jurusan Pendidikan Bahasa Jerman UNM

Romadloni, A., \& Mantasiah, R. Intercultural approach in foreign language learning to improve students' motivation. Senior Editors, 61.

Rosidi, Imron. (2013). Menulis Siapa Takut? (Panduan Bagi Penulis Pemula). Yogyakarta: Kanisius

Saddhono, Kundharu dan St.Y.Slamet. (2012). Meningkatkan Keterampilan Berbahasa Indonesia Teori Dan Aplikasi. Bandung: Karya Putra Darwati. 
Schulz, Dora dan Griesbach, Heinz. (1970).

Grammatik der deutschen

Sprache. München: Max Hueber

Verlag

Steets, Angelika dan Ehlich, Kohrad. (2003).

Wissenschaftlich Schreiben. Lehren und Lernen. Berlin: Water Groyter

Sudiana. (2008). Analisis Penggunaan

Deklinasi Possesivpronomen dalam

kasus Akkusativ dan Dativ Siswa

Kelas XI SMA Negeri 13 Bandung.

(Skripsi). Makassar: Jurusan Bahasa Jerman FPBS UPI

Sugiyono. (2007). Metode Penelitian Administrasi. Bandung: Alvabeta

Suhardi. (2013). Dasar-dasar Ilmu Sintaksis

Bahasa Indonesia. Yogyakarta: ArRuzz Media

Tenri, A., Asri, W. K., \& Azizah, L. (2017).

KEEFEKTIFAN

PENGGUNAAN

MEDIA

BRETTSPIEL

DALAM
BERBICARA BAHASA JERMAN SISWA KELAS $X$ SMA NEGERI 11 MAKASSAR. Eralingua: Jurnal Pendidikan Bahasa Asing dan Sastra, 1(1).

Wardoyo, Sigit M. (2013). Teknik Menulis Puisi. Yogyakarta: Graha Ilmu.

Yusri, Y. (2015). Pelanggaran Kesopanan Berbahasa dalam Komunikasi Politik Pada Pemilihan Gubernur Sulawesi Selatan 2013. PAROLE: Journal of Linguistics and Education, 5(1), 26-39.

Yusri, Y., \& Hidayat, A. R. (2016). Geographical Influences on the Language Skill of Elementary School Students in Lae-Lae Island Makassar City. Humaniora, 28(2), 208-214.

Zainurrahman. (2011). Menulis Dari Teori Hingga Praktik. Bandung: Alfabeta. 